\title{
Quiet rooms
}

Cite as: CMAJ 2020 June 15;192:E662-3. doi: 10.1503/cmaj.191716

was a medical student when I first sat in the quiet room of an emergency

department. I sat with Logan, my roommate and classmate. Neither of us spoke. A thick glass door separated us from the rest of the emergency department. A fan whirred overhead, drowning the cacophony outside.

A security guard walked by. My other roommate, Sarah, opened the door. She had told us she wanted to end her life earlier that night. The three of us looked at each other.

"Guess what? I got formed," she said nonchalantly. We knew what this meant. We learned about it in medical school together. She was placed on an involuntary psychiatric hold. Logan and I could leave now, the security guard said. The corners of Sarah's mouth quivered just a bit.

When I closed my eyes that night, I had flashbacks of Sarah walking into the kitchen, sobbing, trying to speak, gasping for air. I dreamt that I was once again browsing the "Red Button," a website where medical students were told to go if we ever needed help urgently. I dreamt that I once again went down the list of emergency numbers on the Red Button, leaving a trail of frantic voice mails along the way. Running out of options, I texted Logan. Sarah is breaking down. Come, kitchen NOW.

My dreams were punctuated by guilt. The signs were there - the bottles of antidepressants in Sarah's room, the unwashed dishes piling up in the sink, the food rotting in the fridge. Sarah's illness rendered her housebound for days at a time.

She had been struggling to write a final essay for a community health course. That night, the night before the essay was due, her request for an extension was denied.

I dreamt many dreams, but I could not figure out what I could have done differently.

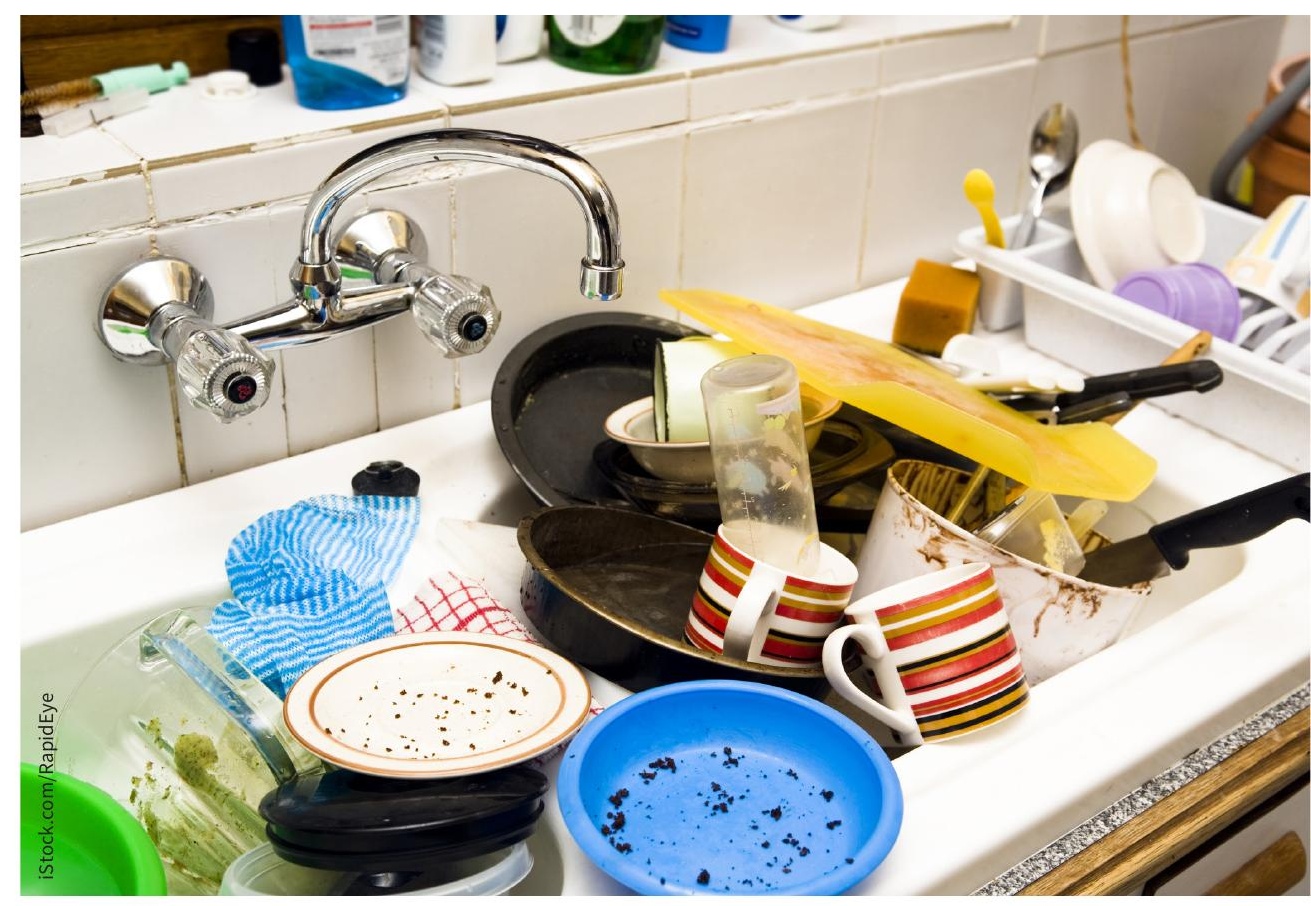

In the middle of the night, I woke up, drenched in sweat. I was afraid of what might have happened had Sarah been alone. I was terrified that the psychiatrist could lift the form in the morning, and Sarah might come home while Logan and I were in class.

I went downstairs to the kitchen and collected every knife I could find. I hid them under my bed. I wanted to feel safe when she returned.

"How did you sleep?" Logan asked the next morning. I saw the light in his room when I collected the knives.

"Terribly," I said.

"I'm exhausted."

I thought, I feel bone-weary.

We went to class together. Neither of us paid attention to the lecture on orthopedic traumas. It felt irrelevant. We left early to visit Sarah on the psychiatric unit.

"Sarah told me she wanted to run into a knife seven times," Logan whispered as we drove to the hospital. "She wanted to jump in front of my car." His expression was flat.
In the psychiatric unit, a television played loudly in the common area. A piano stood in the corner. A patient wearing a hospital gown speed-walked past us. We walked into Sarah's room. It smelled of urine and bleach.

"How are you doing?" I asked Sarah.

"I'm doing better," she said.

I looked around. Through the thick, permanently shut plexiglass windows, I could see the hospital parking lot. I was not sure how Sarah could possibly benefit from the unit. She would not connect with the other patients. She knew the therapy techniques by heart, having studied them for our examinations. I thought, this hospitalization only buys us time.

On our way out, I opened the piano and played a chord. The chord was dissonant, the piano wildly out of tune.

Sarah received an extension on the essay the week after. She was discharged from the psychiatric unit. She came home and slept. 
One evening, I had dinner with a classmate. "How are you doing?" he asked. He looked genuinely concerned. Word travelled fast in our class.

There was much to talk about. I wanted to bring up my dreams. I wanted to describe the palpitations every time I walked past an emergency room. I wanted to talk about how, when I reached out to a mental health worker, I was asked to let Sarah hit rock bottom and to leave her to "professional supports." The advice was sound. I knew I would disregard it.

"I'm managing," I finally said. It was true. My grades were fine.

I went home and put the knives back in our kitchen, one by one.

Sarah spent that entire summer catching up on remaining coursework. She rejoined our class in September. She continued to stay in bed for days at a time. Her dirty dishes piled up. I threw out her food that was rotting in the fridge. I knew she struggled with the 26-hour call shifts of clerkship. Sarah met her psychiatrist periodically, but I had no idea whether
Sarah had discussed her challenges honestly. She knew the right things to say. She told us she was doing okay.

Sarah needed an additional two years to become a family physician. I am proud she graduated.

Medical education taught us to look for signs and symptoms of illness. We learned to define burden of disease. We were our own blind spots.

Sarah, Logan and I never discussed this experience in depth. We did not know how. Years passed before we could see how it changed us. Logan, who had considered a career in psychiatry, became a general surgeon.

I changed too. I now work in the emergency department. My colleagues speak about the stress of clinical practice, although I have yet to sit down with a fellow staff person in the quiet room.

Many of my patients are incredibly bright. Some are medical students, social workers and counsellors. They come to the hospital on evenings and weekends. They tell me about how they try breathing exercises on their way to work to hold off flashbacks. They take medications in between patients to help them manage anxiety. I listen to their stories. If they are suicidal, I form them.

A boyfriend of a patient became indignant recently.

"You're putting her on suicide watch. How is this going to help her feel better?" he confronted me in the quiet room. A security guard stood outside.

He was, of course, right. I looked at him, sitting on the couch, enraged, helpless. I wanted to tell him, this is tough. I sat on that couch once. I get it. But it was the only thing I could do.

\section{Jonathan Ding MD}

Department of Emergency Medicine, Lakeridge Health Ajax Pickering Hospital, Ajax, Ont.

This article has been peer reviewed.

This is a true story. Sarah, Logan and the supportive friend the author met up with over dinner after Sarah's discharge from hospital have all given consent for it to be told. Sarah and Logan are pseudonyms. 